\title{
DIETARY DIFFERENCES BETWEEN GOATS AND SHEEP
}

A.M. NICOL, D.P. POPPI, M.R. ALAM, H.A. COLLINS Department of Animal Science, Lincoln College, Canterbury

Abstract

Goats in pens eat about $20 \%$ more of a low quality feed than do sheep. This higher intake is just sufficient to match the higher maintenance energy requirement of the goats, so, in reality, they are not more suited to an existence on low quality feeds There is little difference between goats and sheep in the extent to which they digest and utilise feeds.

It is clear that goats will eat more browse such as gorse, but under intensive pasture grazing, the dry matter intake of goats falls more rapidly than that of sheep as the herbage mass declines. Goats seem to be unwilling to graze less preferred components of the ward. These results suggest sheep rather than goats have to be used to graze to low herbage masses unless low intakes and performance of goats can be accepted.

\section{INTRODUCTION}

Goats are now recognised as an important species on N.Z. pastoral farms. It is estimated that over 427,000 goats are currently farmed and although these are only $0.06 \%$ of the total stock units (SU) (NZMWEES 1986), it is likely that goat numbers will continue to increase rapidly Goats, like beef cattle and sheep, will probably be farmed in conjunction with other grazing species, particularly sheep.

To function efficiently, mixed farming systems must allow for the specific husbandry requirements of the individual species and exploit any complementarity between the species. To achieve this integration, detailed comparative studies of the species are essential. This paper reviews current knowledge on the similarities and differences between sheep and goats in their digestive physiology and grazing behaviour.

\section{DIGESTIVE PHYSIOLOGY}

\section{Ad Libitum Feed Intake}

The ad libitum feed dry matter intake of sheep and goats offered the same diet in pens has been compared on numerous occasions. In New Zealand with lambs and goats of a similar age (a criterion not always followed in comparative studies), Alam (1985) found the ad lib organic matter intake (OMI) of kids to be $25 \%$ greater than that of lambs when ad lib intake was low (35 $\mathrm{g}$ OM/ $\left.\mathrm{O}^{0.75} / \mathrm{d}\right)$. In individual experiments the advantage to goats on poor quality diets has been as great as $50 \%$.

\section{Digestibility}

Digestibility (the proportion of feed intake disappearing along the whole digestive tract) is the most important single indicator of nutritive value. A small superiority ( 1 to $2 \%$ units) in digestibility by goats over sheep is all that has been observed with feeds of low digestibility (organic matter digestibility (OMD) goats 0.46 , sheep 0.45; Alam et al. 1985). On feeds of higher digestibility $(>0.60)$ there was little difference between the species but sheep tended to show a small advantage. This agrees with most published reports (Devendra 1978).

\section{Digestible Organic Matter or Metabolisable Energy Intake}

The product of OMI and OMD is digestible organic matter intake (DOMI), often simply converted to metabolisable energy (ME) intake by a constant. DOMI or ME intake represents the available nutrient intake and the higher this is, the greater the potential for production. 
Our results show a greater DOMI (25\% higher) intake of goats over sheep fed low quality diets such as straw in pens but this advantage is completely lost with high quality (OMD>0.70) diets (Figure 1) when the DOMI of sheep exceeds that of goats by around $7 \%$. It is the difference in ad lib OMI between the species which contributes almost all of the difference in DOMl; the effect of digestibility differences are small.

Comparative studies on more detailed aspects of ruminant digestion have been made to determine the physiological basis for these differences in DOMI.

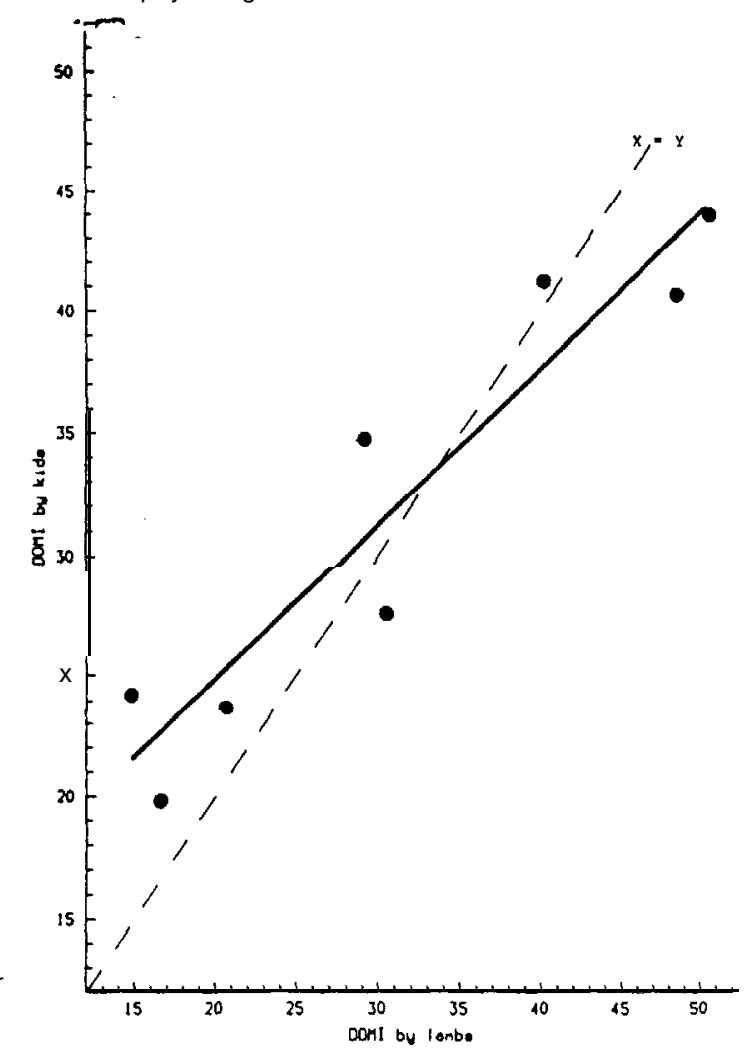

Figure 1: Relationship between DOMI ( $\left./ \mathrm{kgW}^{0 \cdot 75} / \mathrm{d}\right)$ by kids and lambs offered various forages.

\section{Rate of Digestion in the Rumen}

Goats maintain higher rumen $\mathrm{NH}_{3}$ levels than sheep when consuming low quality roughage (e.g. straws), (Watson and Norton 1982; Alam et al. 1985) which appears to be associated with the much lower water intake per unit dry matter intake by goats (Alam 1984; Alam et al. 1985). This higher rumen $\mathrm{NH}_{3}$ concentration may be implicated in the higher intake of low quality forages by goats by its effect on digestion rate. However, recent experiments have shown no differences between the species in the rate of digestion of barley straw when rumen $\mathrm{NH}_{3}-\mathrm{N}$ levels were low $\left(<100 \mathrm{mg} \mathrm{NH}{ }_{3} \mathrm{~N} / \mathrm{l}\right)$ (Tan et al. 1987). 


\section{Sites of Digestion}

It is well recognised in sheep and cattle that differences exist in the site of digestion along the digestive tract of components of the diet, even between feeds which have similar digestibility (MacRae \& Lobley 1983) and that this can have a marked influence on the utilization of absorbed nutrients.

Alam (1985) studied the site of digestion of various nutrients in kids and lambs fistulated at the duodenum and ileum and consuming a very high quality hay (OMD = 0.76). No differences between the species were observed. Such site of digestion studies are being extended to low quality feed types (Tan unpubl. Ph.D Studies).

\section{Metabolisable Energy for Maintenance and Gain}

Few energy balance trials have been run concurrently with goats and sheep and comparisons between the species tend to be made from data derived from different experiments. Balance studies using the comparative slaughter technique on lambs and kids offered a good quality hay $(\mathrm{OMD}=0.76)$ have provided values for $\mathrm{ME}_{\mathrm{m}}$ (the metabolisable energy required for maintenance) and $\mathrm{k}_{\mathrm{g}}$ (the efficiency of utilisation of MD for body gain) (Alam 1985). The values obtained for $\mathrm{ME}_{\mathrm{m}}$ were 0.44 and 0.37 MJME $/ \mathrm{kgW}^{0.75} / \mathrm{d}$ for kids and lambs respectively (an $18 \%$ higher maintenance requirement for kids than lambs). These values compared favourably with values for adult goats and sheep of 0.47 and $0.40 \mathrm{MJME} / \mathrm{kgW}^{0.75} / \mathrm{d}$ respectively (Mohammed \& Owen 1982) and 0.39 for adult goats (Holmes \& Moore 1981). Similarly there was no significant difference in $\mathrm{k}_{\mathrm{g}}$ between the two species, the values being 0.28-0.32 for kids and $0.22-0.27$ for lambs.

\section{Summary}

Comparative physiological studies to date have shown little difference between goats and sheep in the utilization of medium to high quality roughage which can promote liveweight gain. With very high quality feeds, sheep have the potential to consume more per unit bodyweight than goats and thus have a higher production potential. The only marked difference between goats and sheep has occurred in the intake of low quality maintenance or sub-maintenance forage where goats consume more than sheep. However, as goats appear to have a higher maintenance energy requirement, the higher intake by goats will not necessarily mean that goats will lose weight at a slower rate. In practical terms when both species are fed roughage (low, medium or high quality), the most important consideration when allocating feed is the difference in bodyweight between the species rather than any perceived differences in utilization of forage.

\section{DIET SELECTION AND GRAZING INTAKE}

The interaction of an animal with its grazing environment can markedly influence the quantity and quality of its diet through selectivity by the animal and availability/accessability of components in the sward. Different grazing behaviour of sheep and goats could change their relativities based on ad lib pen feeding data.

\section{Diet Selection}

In designing appropriate grazing management systems for goats and sheep, it is essential to have knowledge of the diet likely to be selected by the two species.

\section{Browsing}

There is clear evidence (see Harrington 1982, for a review) that goats will select browse species as part of their diet more readily than sheep, although this may not be so pronounced in Angora goats. This is clearly demonstrated in the work of Radcliffe (1983) and Rolston et al. (1983) on the ability of goats to reduce and control 
gorse and thistles on hill country. Dissection of oesophageal fistula (O/F) samples from goats grazing areas previously ungrazed by them showed that, on average, $62 \%$ of the sample was gorse (Clarke et al. 1982) and Radcliffe (1981) has shown the \% gorse residues in goats faeces to be twice that of sheep when the two species were set stocked together on gorse/pasture communities. However, when grazing areas which for two seasons had been grazed by goats or mixtures of sheep and goats, the contribution of gorse to the diet of goats was low (6\% on average) and the diets of the two species had a considerable overlap (Clarke et al 1982).

A clear distinction needs to be made between the removal of browse species (as a weed?) from a pasture and the maintenance of a proportion of browse in a pasture (as a productive crop?). The comparative use of sheep and goats for the latter in particular requires further study. Alternate grazing of the two species may be indicated if optimum use of the browsing habit of goats is to be achieved.

\section{Grazing}

Where browse is not present, or has been suppressed, more competition between the two species for components of the sward exists. It has been suggested that the preference of sheep for clover is greater than that of goats. For example, Clarke et al. (1982) suggested that sheep eat white clover in proportion to that on offer in the sward while goats reject white clover. However, limited diet selection data from Hughes et al. (1984) failed to show marked differences in the ratio of grass to clover in O/F samples from lambs and kids but a lower proportion of clover in the diet of older goats was observed.

The ability of animals to express their preference for individual components of the sward is limited by sward structure and the availability of each component (L'Huiller et al. 1984). In the Ballantrae work the ratio of grass:clover in the diet in spring and winter was $38: 1$ for both species (Clarke et al. 1982). In the summer and autumn the ratio of grass:clover was lower (i.e. more clover selected) with sheep $(10: 1)$ than with goats $(30: 1)$. Although seasonal changes in herbage mass were not reported by Clarke et al. (1982) they do state that the range was great $(1300-6200 \mathrm{~kg}$ $\mathrm{DM} / \mathrm{ha}$ ) (Lambert et a/. 1981). It is likely that more herbage (higher herbage mass, allowance, residual) would have been available in summer/autumn than in spring/winter and thus any preference of sheep for clover would have been more pronounced where the herbage availability was greater.

Supporting evidence for this latter statement comes from recent work (Collins \& Nicol unpubl) which compared the diet selected by hoggets and young wether goats grazing similar swards (Figure 2). The diet selected by goats varied little as the herbage mass disappeared over a $10 \mathrm{~d}$ period from 3000 to $850 \mathrm{~kg}$ DM/ha, with only a small substitution of stem for leaf and no large increase in the dead material consumed. On the other hand, the major component of the diet of sheep moved progressively from clover to grass leaf, to grass stem, to dead material. Conclusions on the relative preference of goats and sheep for clover are very dependent on the day that the comparison was made. For example on day 1, the proportion of clover in O/F samples from sheep was 6 times that of goats, but from day 5onwards there was no difference in the proportion of clover in the diets selected by the two species.

These data suggest that while sheep may have stronger preferences for particular components of the sward, they are perhaps more willing to change to other components as the preferred components are removed.

In the above work the spatial pattern of grazing was quite different between the two species in that sheep grazing resulted in a patchiness not seen with goats. This is a commonly expressed observation of those working with the two species and suggests that the height to which the species graze may be more limiting to goats than sheep. 


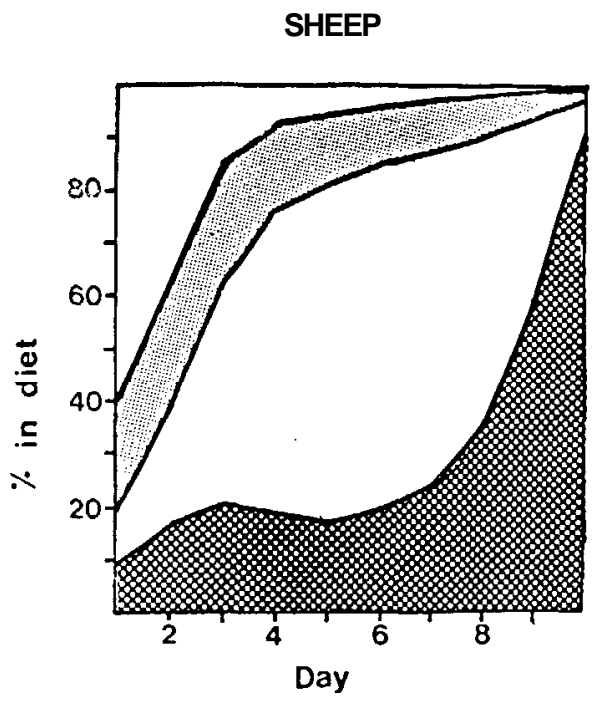

GOATS

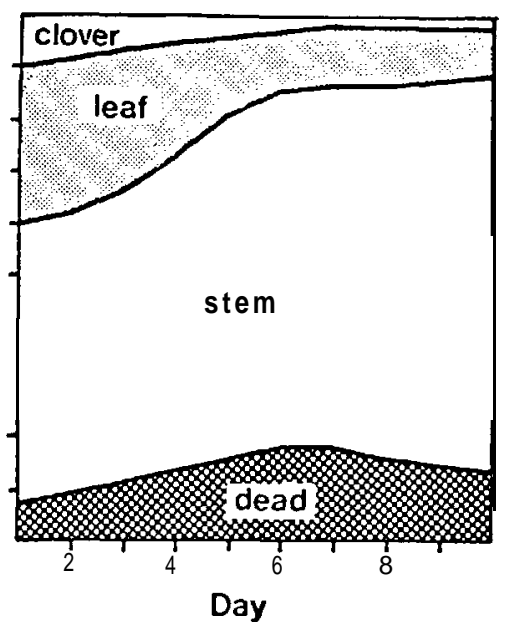

Figure 2: Percentage composition of the diet selected by sheep and goats removing similar quantities of dry matter per day from the same sward over a 10 day period.

Currently our studies have considered the influence of herbage availability on the diet selected and have not considered the importance of the percentage of desired components on offer. Work with sheep has attempted to isolate these two effects (e.g. Milne et al. 1982; Clarke et al. 1982).

Intake

Diet selection studies are useful to determine the quality of the diet consumed and enable conclusions to be drawn as to the potential complementarity or competition between grazing species. However, it is the actual dry matter intake of animals during grazing which has the major effect on productivity. Few intake studies have been made of goats and sheep on similar swards. Recently, the intake (by agronomic measurements) of goats was shown to be very similar to that of sheep when herbage mass was high early in the progressive defoliation of a sward (Table 1).

However, when the herbage mass was decreased by the same quantity of dry matter/ha/day the apparent intake of goats fell more rapidly than that of sheep (Collins \& Nicol 1986). Thus the apparent intake of goats at high herbage mass was 0.98 that of sheep, but this fell markedly to 0.66 at the lower herbage mass (1750 kg $\mathrm{DM} / \mathrm{ha}$ ). The intake of sheep was less sensitive to declining herbage mass than that of goats and this may be related to the ability of sheep to adapt to eating less preferred components of the sward with reduced herbage availability.

The two species seem to respond differently to decreasing herbage availability, its primary influence on goats being to reduce total DM intake where as in sheep, it had a greater influence on selectivity.

These studies on the comparative diet selection and grazing intake of goats and sheep are incomplete, but it is clear that in deriving appropriate grazing strategies for goats and sheep, considerable emphasis must be placed on defining the swards on which they perform satisfactorily and understanding the effect of grazing by one species on the performance of the other. 
Table 1: The apparent dry matter intake $\left(Q \mathrm{DM} / \mathrm{W}^{0 \cdot 7} / \mathrm{d}\right)$ of goats and sheep grazing at the same herbage mass.

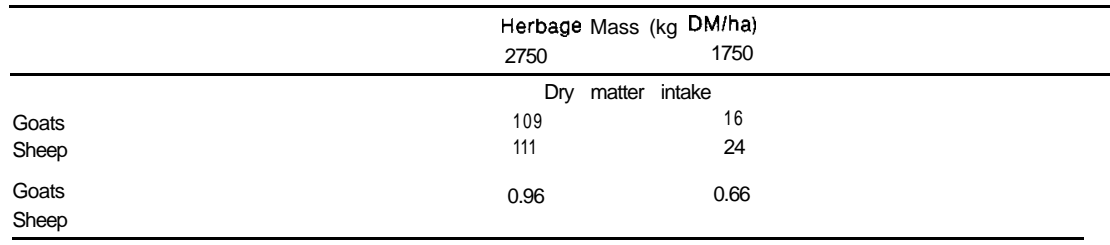

\section{CONCLUSIONS}

Sheep and goats differ in their digestive physiology and grazing behaviour.

In pen feeding situations goats eat more (20\%) of low quality feeds thar: sheep but the difference is reversed on high quality feeds where sheep eat slightly more than goats.

Differences in the digestive physiology of goats and sheep are small. Low quality feeds (DMD $<0.50)$ are digested to a slightly greater extent $(1-2 \%$ units) by goats. Furthermore, there is no current evidence to show that rate of digestion or proportional digestion differs along the digestive tract of the two species but work in this area is continuing.

The maintenance requirements of goats in pens appears to be $20 \%$ greater than of sheep, but results to date show no major difference between the species in the efficiency of utilisation of ME for growth. In general, the higher intake of goats on lower quality feeds only matches their greater maintenance requirements. Thus, in reality goats are not more suited to an existence on low quality feeds.

There are obvious differences in the grazing preferences of goats and sheep which are most markedly expressed (a) when browse is present or (b) as herbage availability changes. Goats consume a wider variety of browse species than sheep and in situations where pasture availability is scarce and browse available, the total herbage available is greater for goats. Under intensive pasture grazing, with no browse species, sheep may be more willing to move from desirable to less desirable components of the sward as pasture availability is reduced, with the result that they are better able than goats to maintain their DM intake in conditions of declining pasture availability.

The response of the two species to variable sward conditions needs to be better understood so that appropriate grazing management systems can be devised.

References

Alam M.R. 1985. Forage utilisation by kids and lambs, Ph.D Thesis, Lincoln College.

Alam M.R., Borens F., Poppi D.P., Sykes A.R. 1964. Comparative digestion in sheep and goats in 'Ruminant Physiology - concepts and consequences' (Ed. S.K. Baker). Univ. W. Aust. 1964. p 164.

Alam M.R., Poppi D.P., Sykes A.R. 1985. Comparative intake of digestible organic matter and water by sheep and goats. Proceedings New Zealand Society Animal Prod. 45: 107-I 11.

Clark D.A., Lambert M.G., Rolston M.P., Dymock N., 1962. Diet selection by goats and sheep on hill country. Proceedings New Zealand Society Animal Production 42: 155-157.

Collins H.A., Nicol A.M., 1966. The consequence for feed dry matter intake of grazing sheep, cattle and goats to the same residual herbage mass. Proceedings New Zealand Society Animal Production 46: in press.

Devendra C. 1976. The digestive efficiency of goats. World Review Animal Production 74: 9-22.

Harrington G.N. 1962. Diet selection in goats. Proceedings 3rd International Conference on Goat Production and Disease, Tuscon, 1962.

Holmes C.W., Moore Y.F. 1961. Metabolisable energy required by feral goats for maintenance and the effects of cold climatic conditions on their heat production. Proceedings New Zealand Society Animal Production 41: 163-166.

Hoppe P.P., Quortrup S.A., Woodford M.H. 1977. Rumen fermentation and food selection in East African ungulates. Journal Agricultural Science (Camb) 89: 129-135.

Hughes T.P., Sykes A.R., Poppi D.P. 1964. Diet selection of young ruminants in late spring. Proceedings New Zealand Society of Animal Production 44: 109-I 12. 
Lambert M.G., Clark D.A., Robson M.P. 1981. The use of goats for coarse weed control in hill country. Proceedings Auakura Farmers Conference 1981 p. 167.

L'Huiller P.J., Poppi D.P. and Fraser T.J. 1984. Influence of green leaf distribution on diet selection by sheep and the implications for animal performance. Proceedings New Zealand Society of Animal Production 44: 105-108.

Macrae J., Lobley G.E. 1982. Some factors which influence thermal energy losses during metabolism of ruminants. Livestock Production Science 9: 447.456

Milne J.A., Hodgson J., Thompson R.I., Souter W.G., Barthram G.T 1982. The diet ingested by sheep grazing wards differing in white clover and perennial ryegrass content. Grass and Forage Science 37: 209.216.

Mohammed H.H. and Owen E. 1980. Comparison of the maintenace requirement of sheep and goats. Animal Production 30: 479 .

NZMWBES 1986. Annual Review of the New Zealand Sheep and Beef Industry 1985.86. New Zealand Meat end Wool Boards Economic Service Pub. 7949, Wellington.

Radcliffe J.E. 1983. Gorse control in Canterbury. Proceedings Ruakura Farmers Conference. pp 59.

Rolston M.P., Clark D.A., Lambert M.G. 1963. Scurb and coarse weed control by goats and sheep: Ballantrae Trial. Proceedings Ruakura Farmers Conference 7983 p. 55

Tan C.M., Poppi D.P., Sykes A.R. 1987.

Watson C., Norton B.W. 1982. The utilisation of pangola grass by sheep and Angora goats. Proceedings of the Australian Society of Animal Production 74: 467.470. 